\title{
Martensitic Transformation, Thermal Analysis and Magnetocaloric Properties of Ni-Mn-Sn-Pd Alloys
}

\author{
Asma Wederni ${ }^{1,2}$, Mihail Ipatov ${ }^{3}$, Eloi Pineda ${ }^{4} \oplus$, Lluisa Escoda ${ }^{1}$, Julian-Maria González ${ }^{3}$, \\ Mohamed Khitouni ${ }^{2}$ and Joan-Josep Suñol 1,* \\ 1 Department of Physics, C/Universitat de Girona 3, Universitat de Girona, 17003 Girona, Spain; \\ asma.wederni@gmail.com (A.W.); lluisa.escoda@udg.edu (L.E.) \\ 2 Laboratory of Inorganic Chemistry, LR-17-ES-07 Université de Sfax, BP 1171, Sfax 3000, Tunisia; \\ mohamed.khitouni@fss.rnu.tn \\ 3 Department of Applied Physics, EUPDS, UPV/EHU, 20018 San Sebastián, Spain; mihail.ipatov@ehu.es (M.I.); \\ julianmaria.gonzalez@ehu.es (J.-M.G.) \\ 4 Departement of Physics, Institute of Energy Technologies, Universitat Politècnica de Catalunya, \\ 08019 Barcelona, Spain; eloi.pineda@upc.edu \\ * Correspondence: joanjosep.sunyol@udg.edu; Tel.: +34-972-41-8490
}

Received: 9 November 2020; Accepted: 25 November 2020; Published: 1 December 2020

\begin{abstract}
Martensitic transition and magnetic response of $\mathrm{Ni}_{50-\mathrm{x}} \mathrm{Pd}_{\mathrm{x}, \mathrm{y}} \mathrm{Mn}_{36} \mathrm{Sn}_{14-\mathrm{y}}(\mathrm{x}=0,1,2$ and $y=0,1)$ Heusler alloys were analysed. The crystalline structure of each composition was solved by X-ray diffraction pattern fitting. For $\mathrm{x}=1$ and 2, the $\mathrm{L} 2{ }_{1}$ austenite structure is formed and, for $y=1$, the crystallographic phase is a modulated martensitic structure. From differential scanning calorimetry scans, we determine characteristic transformation temperatures and the entropy/enthalpy changes. The temperatures of the structural transformation increase with the addition of Pd to replace $\mathrm{Ni}$ or $\mathrm{Sn}$, whereas the austenitic Curie temperature remains almost unvarying. In addition, the magneto-structural transition, investigated by magnetic measurements, is adjusted by suitable Pd doping in the alloys. The peak value of the magnetic entropy changes reached $4.5 \mathrm{~J} /(\mathrm{kg} \mathrm{K})$ for $\mathrm{Ni}_{50} \mathrm{Mn}_{36} \mathrm{Sn}_{13} \mathrm{Pd}_{1}$ (external field: $50 \mathrm{kOe}$ ).
\end{abstract}

Keywords: magneto-structural transition; Heusler alloys; martensitic transition; magnetocaloric effect; entropic change

\section{Introduction}

Nowadays, the surveys of high-temperature shape memory alloys, so-called Heusler alloys, are gathering wide-reaching attention, because of their potential in developing new-fangled smart actuators with boosted purposeful properties. Typically, shape memory alloys (SMAs) are exploited, in bioengineering, medicine, aerospace, composites and micro electromagnetic components [1]. Some Heusler alloys display mutually ferromagnetic and shape memory properties at the same time, and both effects can be tuned by temperature, pressure and/or magnetic field. These effects are attributed to a first-order martensitic transformation through a robust magneto-structural coupling in which a cubic high-temperature parent austenite phase transforms into a low ordered martensite phase by dropping the temperature. Martensite can be modulated (atomic sites deviate in a quite periodic way) [2], the martensitic domains move and permit the creation of large macroscopic deformations in the sample. In this case, the crystalline structure remains intact (the displacement is due to domain walls). Therefore, this deformation does not require a huge amount of energy [3].

In general, transition temperatures in SMAs strongly depend on the chemical composition [4]. The transformation temperatures in these types of alloys are determined by thermal analysis and/or 
vibrating sample magnetometry [5]. Generally, Ni-Mn-based alloys have enticed much consideration due to their applicability in magnetic refrigeration (MR). This technology is based on the so-called magnetocaloric effect (MCE) is an alternative cooling method for prevalent vapour compression refrigeration technology [6]. It is worth remarking that MR is an environmentally friendly technology. Once a magnetic field is applied, the change in magnetic entropy $\left(\Delta \mathrm{S}_{\mathrm{M}}\right)$ causes the magnetocaloric effect (defined as direct MCE when the total entropy change is negative and inverse MCE when total entropy change is positive) [7]. Among several alloys showing first-order magneto-structural transformation (FOMT), giant MCE has been reported in different Ni-Mn-(Sn,In) alloys [8]. It was also well-identified that in metamagnetic systems, the inverse magnetocaloric occurring on applying isothermal magnetization and adiabatic magnetization relies on field-induced reverse martensitic transformation and the cooling stems from the latent heat of the structural transformation. This is advantageous for reaching a large magnetic entropy change at a low external field [9]. Aside from large $\Delta \mathrm{S}_{\mathrm{M}}$ values, the cooling power (RCP) is considered to be a significant parameter to evaluate the potential of refrigerant materials. Likewise, the addition of a fourth element to Ni-Mn-Sn systems is a current strategy to tune the structural-magnetic transformations and the magnetic behaviour of SMAs, enhancing the properties even though it can also modify the structure [10]. Numerous quaternary systems have been established, such as those with the addition of $\mathrm{Cu}$ [11], Co [12], Fe [13], W [14] or $\mathrm{Pd}$ [15]. The additions usually produce a shift of the transformation temperatures. Thus, controlled addition is a way to tune transformations close to room temperature. Fe addition favours the diminution of the structural transformation temperature, whereas the $\mathrm{Co}$ or $\mathrm{Cu}$ addition usually provokes the increase in the temperatures, depending on what element is substituted. A parameter has been defined that influences MT temperatures-e/a (average outer electron concentration per atom) [16], which offers a suitable way to control the transition temperature. Likewise, the stoichiometry Heusler structure is $\mathrm{X}_{50} \mathrm{Y}_{25} \mathrm{Z}_{25}$ (also described as $\mathrm{X}_{2} \mathrm{YZ}$ ) and some articles analyse the influence on the characteristic temperatures and magnetic response of the addition of a fourth element taking into account the expected site position of this additional element, usually $\mathrm{X}$ or $\mathrm{Z}$ sites [11,15].

Concerning Pd addition, S.Y. Dong et al. have reported that the lattice parameter and the martensite transformation temperature increases gradually in $\mathrm{Ni}_{50-x} \mathrm{Mn}_{36} \mathrm{Sn}_{14} \mathrm{Pd}_{\mathrm{x}}$ with the increase in Pd content [15]. Likewise, R. Saha et al. have observed the same effect. We also observed that the replacement of $\mathrm{Pd}$ in $\mathrm{Ni}_{50-x} \mathrm{Pd}_{x} \mathrm{Mn}_{37} \mathrm{Sn}_{13}$ rises the refrigerant capacity (RC) near room temperature [17]. However, the predictable values of MCE parameters, such as the isothermal $\Delta \mathrm{S}_{\mathrm{M}}$ and RC, unavoidably should be validated from magnetic measurements.

In this work, we produced $\mathrm{Ni}_{50-\mathrm{x}} \mathrm{Pd}_{\mathrm{x}, \mathrm{y}} \mathrm{Mn}_{36} \mathrm{Sn}_{14-\mathrm{y}}(\mathrm{x}=0,1,2$ and $\mathrm{y}=0,1)$ alloys with $\mathrm{Pd}$ addition to replace $\mathrm{Ni}$ or $\mathrm{Sn}$. If compared with stoichiometry Heusler structure $\left(\mathrm{X}_{50} \mathrm{Y}_{25} \mathrm{Z}_{25}\right)$, for $\mathrm{x}=1,2$ is expected that $\mathrm{Pd}$ substitution of $\mathrm{Ni}$ is performed in $\mathrm{X}$ sites whereas for $\mathrm{y}=1$ the Pd substitution of $\mathrm{Sn}$ in $\mathrm{Z}$ sites.

We aspire to interpret the impact of the addition of non-magnetic Pd element (in Ni or Sn sites of the Heusler off-stoichiometric crystallographic structure) on the magnetic structure and the phase transformation features. This will allow the control of the structural transition and the production of Ni-Mn-Sn materials with an excellent magnetic response. The influence on the crystallographic structure and transition temperatures is also studied.

\section{Materials and Methods}

The polycrystalline $\mathrm{Ni}_{50-\mathrm{x}} \mathrm{Pd}_{\mathrm{x}} \mathrm{Mn}_{36} \mathrm{Sn}_{14-\mathrm{y}}(\mathrm{x}=0,1$ and 2$)$ and $(\mathrm{y}=0,1)$ alloy ingots were obtained by arc-melting in a mould from high purity Ni, Pd, Mn and Sn (Sigma Aldrich, Saint Louis, MO, USA) under Ar atmosphere, the chamber was purged (Ar, vacuum) numerous times. Then, the rounded ingots that come from this melting were re-melted three times to reduce compositional inhomogeneity. Afterwards, the bulk samples were melt-spun. Processing conditions were: $10^{-4}$ torr vacuum, wheel $40 \mathrm{~m} \mathrm{~s}^{-1}$ linear surface velocity. All this process takes place under a protective argon atmosphere. 
By this melt spinning technique, ribbon-flake samples were obtained. Additional information about processing and analysis can be found in references [3,4,11].

To determine the crystalline phase of the as-spun ribbons, we used a Panalytical Empyrean diffractometer with $\mathrm{Cu}-\mathrm{K} \alpha$ radiation. Rietveld refinement method was applied using the Maud software [18]. The phase-transition temperatures were obtained by differential scanning calorimetry (DSC) in a DSC822 Mettler-Toledo calorimeter (Metller-Toledo, Billerica, MA, USA). To perform the thermal cycling scans, we employed a cooling and heating rate of $10 \mathrm{~K} / \mathrm{min}$, under Ar atmosphere. Finally, all the thermomagnetic measurements were performed in a vibrating sample magnetometer, Quantum Design PPMS Model P525 VSM module; Lake Shore Cryotronics, Westerville, OH, USA). Zero-field-cooling (ZFC), field-cooling (FC) and field-heating (FH) measurements were performed between 10 and $400 \mathrm{~K}$ (external magnetic field up to $50 \mathrm{kOe}$ ). The magnetic entropy change was determined from isothermal magnetization measurements.

\section{Results and Discussion}

\subsection{XRD Analysis}

The room temperature XRD diffraction patterns of $\mathrm{Ni}_{50-x} \mathrm{Pd}_{x} \mathrm{Mn}_{36} \mathrm{Sn}_{14}(\mathrm{x}=1$ and $2 ; \mathrm{y}=1)$ are given in Figure 1. The XRD patterns of $\mathrm{Ni}_{50-x} \mathrm{Pd}_{x} \mathrm{Mn}_{36} \mathrm{Sn}_{14}(\mathrm{x}=1$ and 2$)$ can be indexed considering a cubic single-austenite phase with the extremely ordered $\mathrm{L} 2{ }_{1}$ crystalline structure (Fm-3m space group). Thus, the martensitic transition is expected below room temperature (RT).
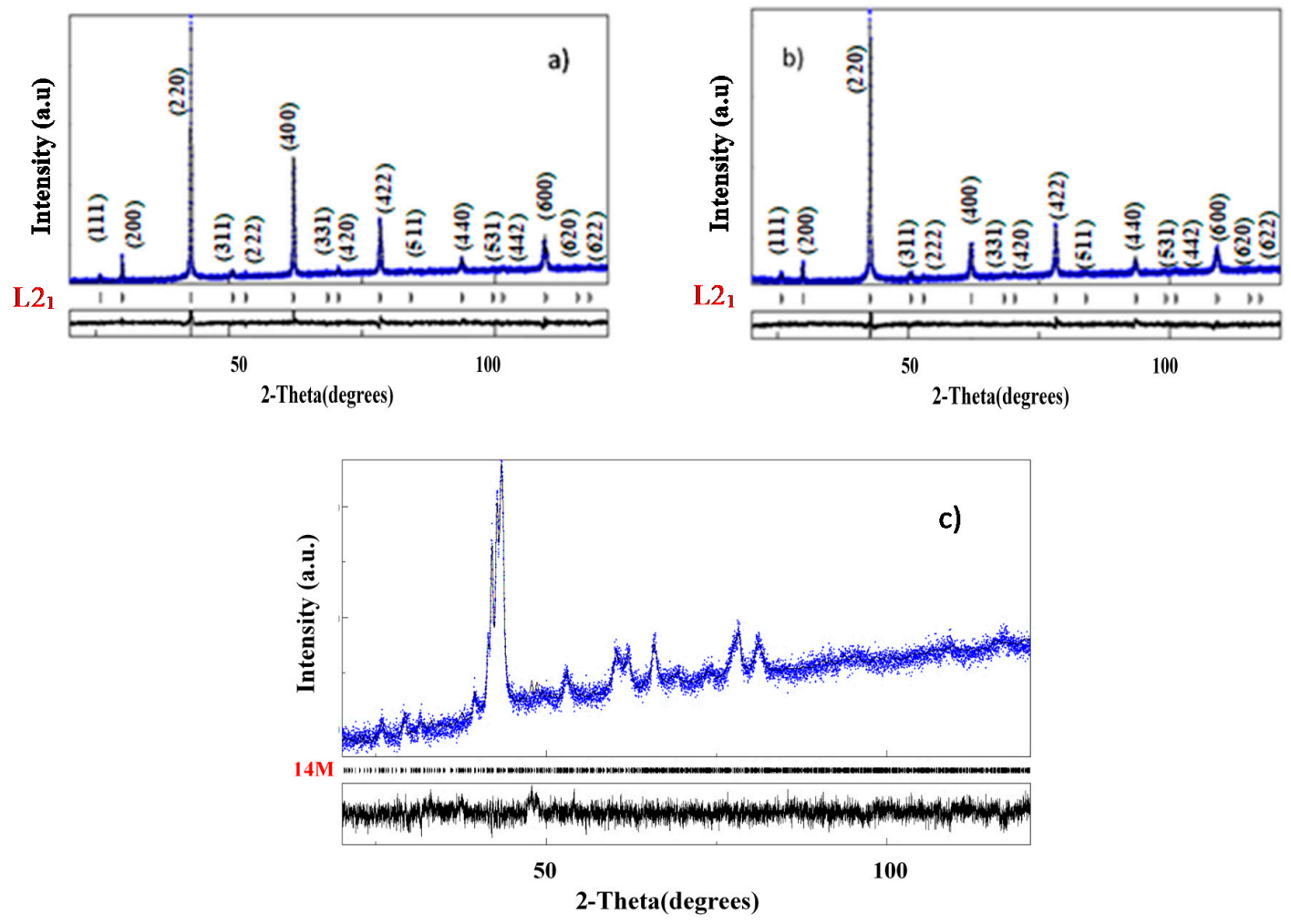

Figure 1. X-ray diffraction (XRD) diffractograms at room temperature: (a) $\mathrm{Ni}_{49} \mathrm{Mn}_{36} \mathrm{Sn}_{14} \mathrm{Pd}_{1}$, (b) $\mathrm{Ni}_{48} \mathrm{Mn}_{36} \mathrm{Sn}_{14} \mathrm{Pd}_{2}$, and (c) $\mathrm{Ni}_{50} \mathrm{Mn}_{36} \mathrm{Sn}_{13} \mathrm{Pd}_{1}$.

The lattice parameters for these samples are 5.993(2) and 6.001(2) $\AA$, for $x=1$ and 2 respectively. Figure $1 \mathrm{c}$ shows the XRD diffractogram of the $\mathrm{Ni}_{50} \mathrm{Mn}_{36} \mathrm{Sn}_{13} \mathrm{Pd}_{1}$ sample (RT). The experimental XRD pattern is well-refined with a monoclinic martensite structure ( $\mathrm{P} 2 / \mathrm{b}$ space group). The lattice parameters are $\mathrm{a}=4.688(2) \AA, \mathrm{b}=6.094(2) \mathrm{nm}, \mathrm{c}=31.593(1) \mathrm{nm}$ and $\beta=92.35^{\circ}$. This monoclinic phase has a $14 \mathrm{M}$ modulation along the $c$ direction. 
As showed in Figure 2, evidence is found that the 220 peak/reflection shifts to a lower angle when we increase the substitution of $\mathrm{Ni}$ by Pd, leading to the growth of cell volume. Analogous behaviour was also observed in $\mathrm{Ni}_{50-x} \mathrm{Mn}_{36} \mathrm{Sn}_{14} \mathrm{Pd}_{\mathrm{x}}$ samples [15], confirming that this effect is probably due to the substitution of larger Pd addition (1.79 $\AA$ ) in previous Ni sites (1.62 $\AA$ ). It is known that the characteristic martensitic start transformation temperature in Heusler samples is powerfully affected by the Mn-Mn interatomic distances [19]. Nevertheless, the detected difference in the lattice parameter a, in our work, is not significant (around $0.008 \mathrm{~nm}$ ), indicating that the martensitic start temperature (Ms) shift is not here linked to the change of Mn-Mn length separation. It is probably due to the e/a parameter [16]. The calculated values of e/a are 8.02 and 7.96 for $\mathrm{x}=1,2$ respectively; and 8.08 for $\mathrm{y}=1$ alloy. Lowering e/a increases the lattice parameter and cell volume. Concerning the occupation of crystallographic sites in these types of alloys, in the case of $\mathrm{Ni}_{2} \mathrm{MnSn}$ stoichiometric Heusler alloys $\mathrm{Ni}, \mathrm{Mn}$ and Sn occupy specific crystallographic sites as remarked and described in reference [20]. However, in our off-stoichiometric $\mathrm{Ni}_{2} \mathrm{Mn}_{1+x} \mathrm{Sn}_{1-x}$ composition, some $\mathrm{Sn}$ sites might be occupied by the excess of Mn atoms. Consequently, Mn has Mn atoms as adjacent neighbours (1 10 direction). As a consequence, the Mn-Mn length separation is smaller than that of stoichiometry [12]. In the case of $\mathrm{Ni}_{50-\mathrm{x}} \mathrm{Mn}_{36} \mathrm{Sn}_{14} \mathrm{Pd}_{\mathrm{x}}$ alloys, the impact of the e/a ratio can be eliminated, as $\mathrm{Ni}$ and $\mathrm{Pd}$ are both positioned in the $\mathrm{X}$ position of $\mathrm{X}_{2} \mathrm{YZ}$ Heusler alloys.

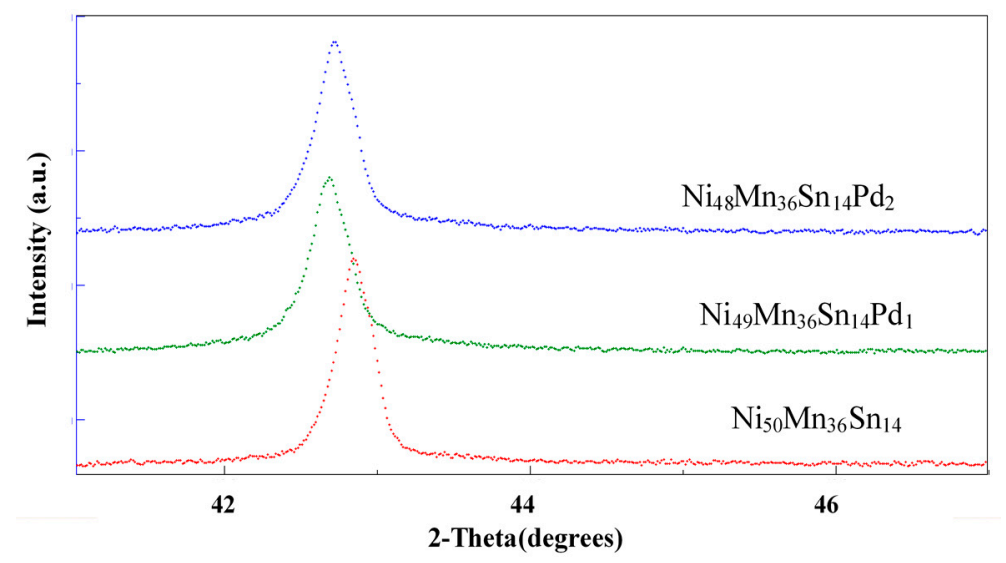

Figure 2. XRD diffraction patterns of alloys with Pd (enlargement of 220 peaks).

All the diffractograms are indexed and successfully refined by applying the Rietveld refinement and the Maud software (version 2,94, free software, university of Trento, Trento, Italy) [21]. It is found a good fitting between experimental and calculated patterns, except for the maximum of some peaks. The slight discrepancy in the intensity of peaks is probably owing to the texture effect and anisotropy favoured by the rapid solidification in the melt-spinning process [22]. The goodness of fit (GOF) parameter has values in the 1.095 to 1.165 interval.

Likewise, from the XRD diffraction patterns a polycrystalline structure can be assumed. The relative intensity of the $\mathrm{L} 2{ }_{1}$ reflections differs in the different samples, as an example the ratio between 400 and 422 reflections. It is well kwon [4] that melt-spun ribbons are polycrystalline and formed by equiaxed grains in the surface in contact with the rotating wheel and by columnar grains between these grains and the free surface of the alloy. The nanocrystalline structure might difficult the transition to martensite phase and move it to lower temperatures [11].

\subsection{Thermal Analysis}

In order to further clarify the transition temperatures and thermodynamic parameters (enthalpy, entropy) in Ni-Mn-Sn-Pd samples, we measured DSC cooling/heating curves in every composition (including the Pd free composition for comparison), as illustrated in Figure 3. These curves demonstrate sharp exothermic and endothermic peaks with restrained thermal hysteresis. These are indicative of a 
first-order phase transition, to martensitic (upon cooling) and, reversely, to austenitic (upon heating) [23]. The peaks observed in the DSC curves are rising from the heat associated with the martensite-austenite formation. One perceptibly notices the existence of small additional peaks, detected during both heating and cooling of $\mathrm{Ni}_{50} \mathrm{Mn}_{36} \mathrm{Sn}_{13} \mathrm{Pd}_{1}$. It is not due to the Curie transition $\left(\mathrm{T}_{\mathrm{c}}{ }^{\mathrm{A}}\right)$ of the austenite [24] because there is a significant hysteresis. It is probably due to a secondary phase, which subsidizes the transformation. Nevertheless, the absence of a second thermal process verified by XRD and VSM suggests that is minority and metastable. Such a behaviour was also reported by P. Czaja et al. [25].
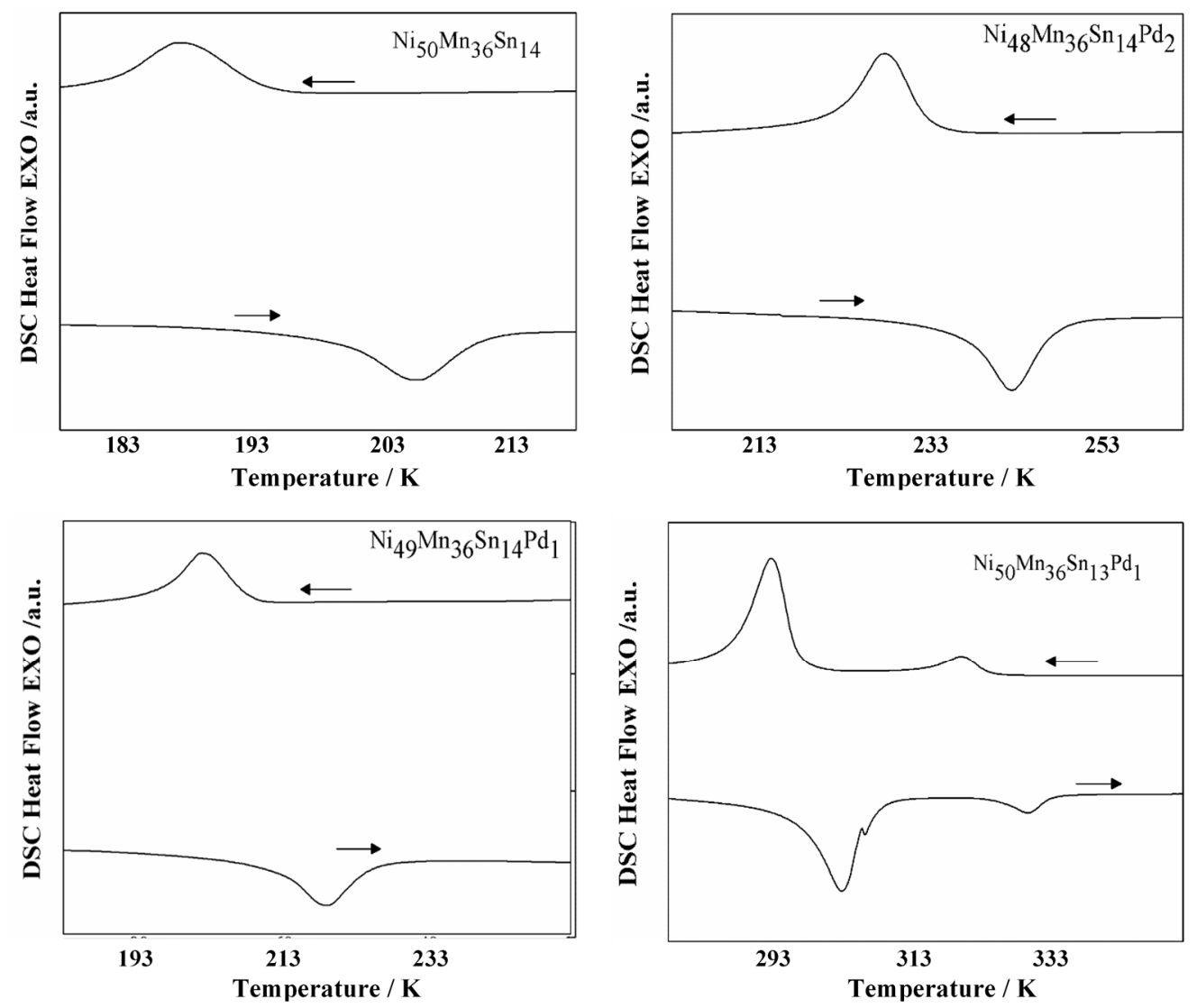

Figure 3. Differential scanning calorimetry (DSC) scans of the direct and inverse martensitic transformation.

It is found that the martensitic transformation of $\mathrm{Ni}_{50} \mathrm{Mn}_{36} \mathrm{Sn}_{13} \mathrm{Pd}_{1}$ sample is just below RT, while for $\mathrm{Ni}_{50} \mathrm{Mn}_{36} \mathrm{Sn}_{14}, \mathrm{Ni}_{48} \mathrm{Mn}_{36} \mathrm{Sn}_{14} \mathrm{Pd}_{1}$ and $\mathrm{Ni}_{49} \mathrm{Mn}_{36} \mathrm{Sn}_{14} \mathrm{Pd}_{2}$ alloys it is much lower. This conclusion correlates well with the XRD analysis. The initial (start) and final (finish) transformation temperatures linked to austenite and martensite reversible formation were assessed from the DSC peaks. When comparing $\mathrm{x}=0$ to $\mathrm{x}=1$ and $\mathrm{x}=0$ to $\mathrm{x}=2$ alloys, the martensite start change is significant $\Delta \mathrm{Ms}=14 \mathrm{~K}$ and $39 \mathrm{~K}$, respectively. A more important $\Delta \mathrm{Ms}$ is found due to the substitution of 1 at. $\% \mathrm{Pd}$ in the $\mathrm{y}=1$ alloy ( $\mathrm{Z}$ site of the Heusler structure).

The martensitic transformation occurs when an extra amount of chemical energy surpasses the difference in Gibbs $\Delta \mathrm{G}$ free energy between the austenite and martensite phases. Subsequently, a drop in Ms should be predictable when $\Delta \mathrm{G}$ grows [26]. The thermal hysteresis provokes that in a temperature interval both Gibbs energies should be extrapolated. Likewise, from the calorimetric data, the entropy change $(\Delta S)$ can be determined by integration [27]:

$$
\Delta S=\int_{T_{S}}^{T f} \frac{1}{T}\left(\frac{d Q}{d t}\right)\left(\frac{d T}{d t}\right)^{-1} d T
$$


The integrals were mathematically calculated, where $\mathrm{dQ} / \mathrm{dt}$ is the heat exchange $(\mathrm{Q}$ is the area of DSC peak), dT/dt is the heating or cooling rate and Ts and Tf are the initial and final temperatures of the austenitic/martensitic transition. All the thermodynamic parameters $(\Delta H, \Delta S)$ and characteristic temperatures are collected in Table $1 . \mathrm{T}_{0}$ is the thermodynamic equilibrium temperature defined as [28]:

$$
\mathrm{T}_{0}=\frac{1}{2}\left(\mathrm{M}_{\mathrm{s}}+\mathrm{A}_{\mathrm{f}}\right)
$$

Table 1. The austenite and martensite formation temperatures $\left(A_{s}, A_{f}, M_{s}\right.$ and $\left.M_{f}\right)$ and the thermodynamic parameters (enthalpy and entropy); (h) heating, (c) cooling.

\begin{tabular}{cccccccc}
\hline Alloy & $\mathbf{M}_{\mathbf{s}} / \mathbf{K}$ & $\mathbf{M}_{\mathbf{f}} / \mathbf{K}$ & $\mathbf{A}_{\mathbf{s}} / \mathbf{K}$ & $\mathbf{A}_{\mathbf{f}} / \mathbf{K}$ & $\mathbf{T}_{\mathbf{0}} / \mathbf{K}$ & $\Delta \mathbf{H} / \mathbf{J} \mathbf{g}^{-\mathbf{1}}$ & $\Delta \mathbf{S} / \mathbf{J ~ g}^{-\mathbf{1}} \mathbf{K}^{-\mathbf{1}}$ \\
\hline $\mathrm{Ni}_{50} \mathrm{Mn}_{36} \mathrm{Sn}_{14}$ & 194.09 & 182.75 & 198.89 & 212.75 & 203.42 & $\begin{array}{l}\text { (h) } 1.573 \\
\text { (c) } 1.516\end{array}$ & $\begin{array}{c}\text { (h) } 0.0078 \\
\text { (c) } 0.00758\end{array}$ \\
\hline $\mathrm{Ni}_{50} \mathrm{Mn}_{36} \mathrm{Sn}_{13} \mathrm{Pd}_{1}$ & 295.85 & 286 & 296.6 & 307 & 301.425 & $\begin{array}{l}\text { (h) } 0.626 \\
\text { (c) } 0.612\end{array}$ & $\begin{array}{l}\text { (h) } 1.595 \\
\text { (c) } 1.633\end{array}$ \\
\hline $\mathrm{Ni}_{49} \mathrm{Mn}_{36} \mathrm{Sn}_{14} \mathrm{Pd}_{1}$ & 208.76 & 193 & 211.8 & 225 & 216.88 & $\begin{array}{l}\text { (h) } 1.539 \\
\text { (c) } 1.332\end{array}$ & $\begin{array}{l}\text { (h) } 0.0035 \\
\text { (c) } 0.0030\end{array}$ \\
\hline $\mathrm{Ni}_{48} \mathrm{Mn}_{36} \mathrm{Sn}_{14} \mathrm{Pd}_{2}$ & 233.26 & 219.2 & 219.2 & 247 & 240.13 & $\begin{array}{l}\text { (h) } 2.939 \\
\text { (c) } 2.994\end{array}$ & $\begin{array}{l}\text { (h) } 0.0122 \\
\text { (c) } 0.0124\end{array}$ \\
\hline
\end{tabular}

To well recognize the impact of Pd substitution on the martensite phase transition, further insight into the e/a parameter for these alloys was analysed. In order to compute the e/a ratio, we take into account the electrons of the outer shells of each element constituting the alloy system. As reported in the literature [29], a linear relationship is expected between the structural phase transition and e/a value. Thereby, e/a and Ms have the same tendency and increase monotonically [30]. The higher the e/a, the higher the temperatures of the structural transformation. Ms raises with the substitution of $\mathrm{Pd}$ for $\mathrm{Ni}$ and $\mathrm{Sn}$. Meanwhile, in $\mathrm{Ni}_{50-\mathrm{x}} \mathrm{Mn}_{36} \mathrm{Sn}_{14} \mathrm{Pd}_{\mathrm{x}}$ alloys, the impact of e/a can be discarded, as though $\mathrm{Ni}$ and $\mathrm{Pd}$ are both probably positioned in $\mathrm{X}$ sites of the Heusler structure.

\subsection{Magnetic Analysis}

The evolution of the magnetization versus temperature, $\mathrm{M}(\mathrm{T})$, of the samples (ribbon flakes) was measured with the ZFC, FC and FH approaches. The samples were firstly cooled down to $10 \mathrm{~K}$ in zero field. To obtain the ZFC magnetization curve, a magnetic field was applied to the sample and we measure the magnetization on heating with the field fixed. Later, the sample was cooled by applying the same field, and the FC (cooling) magnetization curve was obtained. Finally, the FH curve was obtained by heating the ribbon flake to $400 \mathrm{~K}$ (procedure described in reference [11]). The evolution of magnetization for all samples (measurements at external magnetic fields of 50 Oe and 50 KOe) are shown in Figures 4 and 5, respectively. Both FC and ZFC curves display information about reversible-irreversible processes owing to the hysteresis of the forward and inverse martensitic transitions. The hysteresis determined by ZFC and FC is a representative feature of magnetic first-order structural transformation.

Figure 4 shows that the magnetization presents a thermal hysteresis at $194.09 \mathrm{~K}, 208.76 \mathrm{~K}$, 233.26 $\mathrm{K}$ for $\mathrm{x}=0,1$ and 2 respectively (selected temperatures are those of martensite start). As the temperature increases, a fast decrease in the $\mathrm{M}(\mathrm{T})$ curves near $310 \mathrm{~K}$ is observed, associated with the Curie temperature. This proves the existence of a ferro-paramagnetic transformation. The magnetic transformation is found in the temperature range corresponding to the austenite phase, $\mathrm{T}_{C}{ }^{\mathrm{A}}$. It should be remarked that the martensitic transformation can appear at temperatures above or below the magnetic one [31]. 

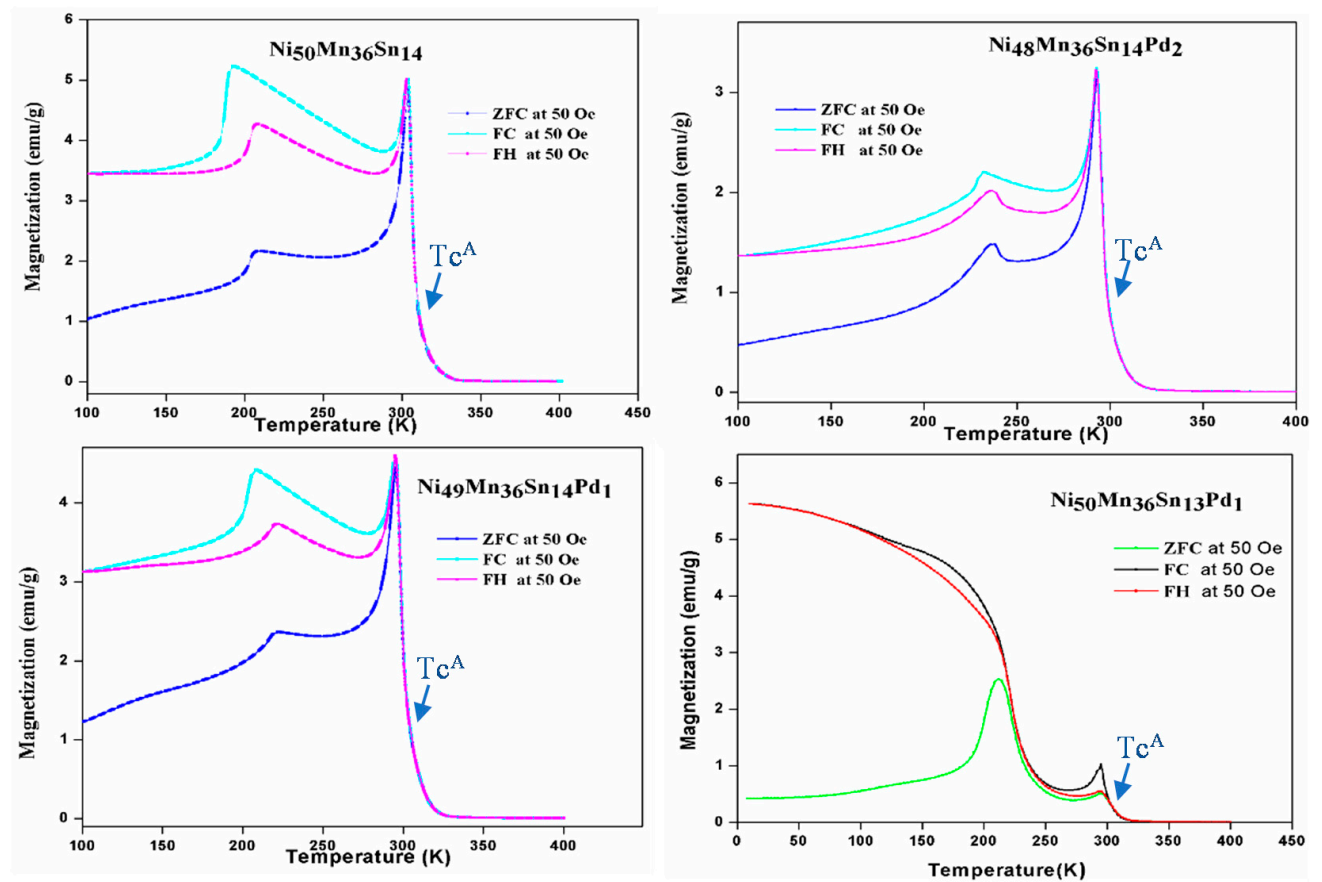

Figure 4. Magnetization as a function of temperature (applied field: 50 Oe).
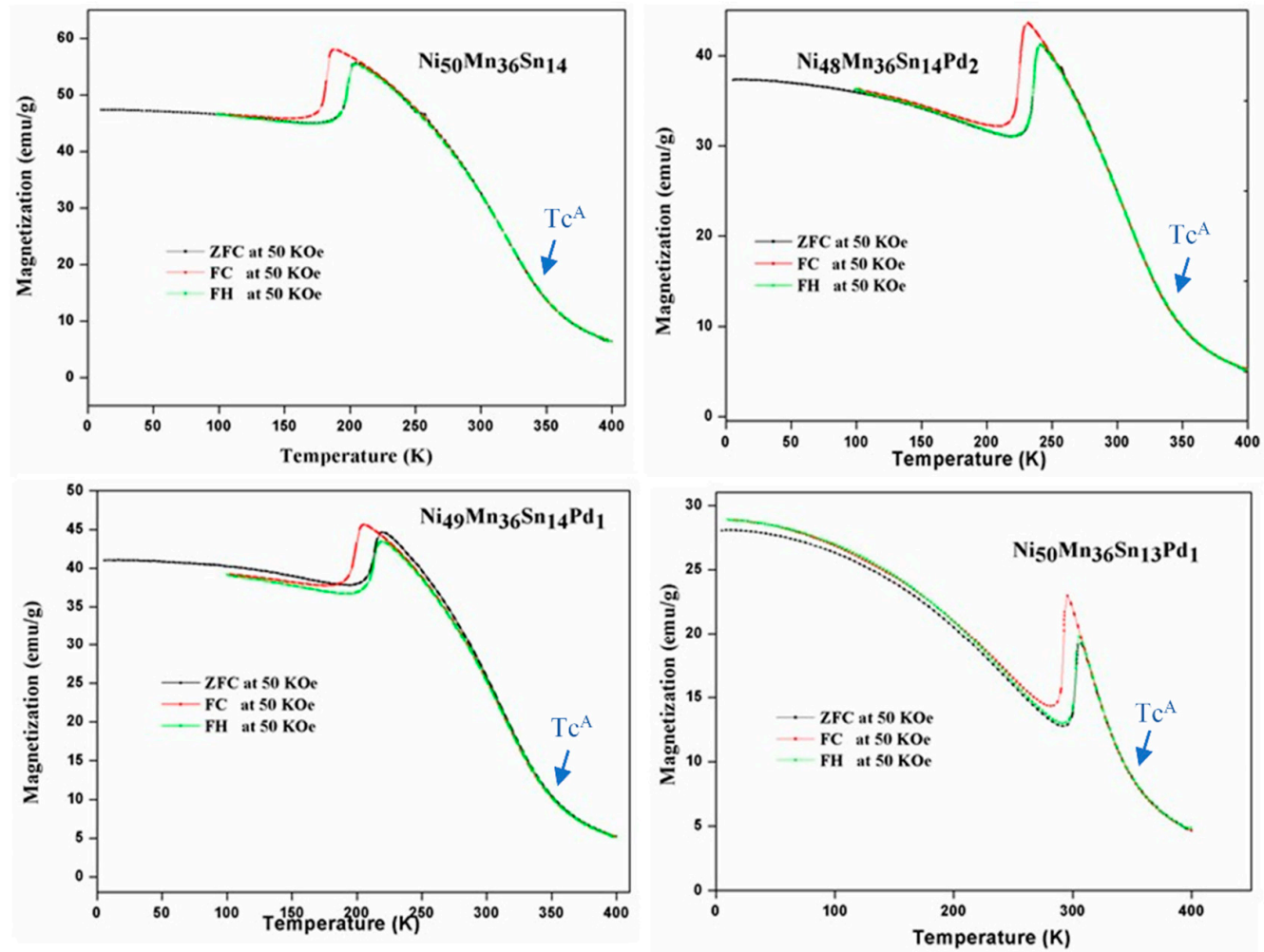

Figure 5. Magnetization as a function of temperature (applied field: $50 \mathrm{kOe}$ ).

More complex behaviour is shown in the $\mathrm{y}=1$ sample. Below the Ms temperature, the magnetization displayed a minor increase upon cooling, of around $(2-6 \mathrm{emu} / \mathrm{g})$. This proposes that the Curie transition of the martensite $\left(\mathrm{T}_{\mathrm{C}}{ }^{\mathrm{M}}\right)$ occurs at temperatures below the martensite start temperature, whereas $T_{C}{ }^{A}$ is close to $310 \mathrm{~K}$. As their temperature $T_{0}$ is $301.425 \mathrm{~K}$, the proximity of both transformations makes this alloy a good candidate for applicability near room temperature. 
As for $(\mathrm{y}=1) \mathrm{Ni}_{50} \mathrm{Mn}_{36} \mathrm{Sn}_{13} \mathrm{Pd}_{1}$, the magnetization was not very clear we proceed to the same magnetization process by applying a larger magnetic field; $50 \mathrm{kOe}$. As is apparent, a high value of applied magnetic field is associated to a higher stabilization of the martensite [11].

The austenite to martensite transition moves to a higher temperature as increasing the external magnetic field, because more energy is needed to reach the martensitic state [32]. Figure 5 illustrates the Curie transition of the austenite, always around $350 \mathrm{~K}$. The martensitic transition for all alloys is found below the Curie transition.

On reaching the Ms temperature, for all Heusler alloys, the magnetization accentuates a crucial drop. Thereafter upon extra cooling, we observe a quick growth at $\sim 250 \mathrm{~K}$, which is symptomatic of the Curie transition of the martensite $\left(\mathrm{T}_{\mathrm{C}}{ }^{\mathrm{M}}\right)$.

Henceforth, the magnetization sequence should undergo the order of $\mathrm{T}_{C}{ }^{\mathrm{M}}<\mathrm{Ms}<\mathrm{T}_{C}{ }^{\mathrm{A}}$ [33]. Nevertheless, here, the martensite phase appears as weakly magnetic above $T_{C}{ }^{M}$ and below $M_{f}$. Likewise, it can be observed that only $\mathrm{Ni}_{50} \mathrm{Mn}_{36} \mathrm{Sn}_{13} \mathrm{Pd}_{1}$ shows $\mathrm{Ms}$ around room temperature and $\mathrm{T}_{\mathrm{C}}{ }^{\mathrm{M}}<\mathrm{Ms}<\mathrm{T}_{\mathrm{C}}{ }^{\mathrm{A}}$. Thereby, this alloy was considered to be the best candidate for magnetocaloric applications [34]. Furthermore, hysteresis cycles at $50 \mathrm{~K}$ are displayed in Figure 6 for all the Heusler alloys. These hysteresis curves clearly show the ferromagnetic soft ordering for all the ribbons. One may observe the magnetically soft character of austenitic phases from small hysteresis loops (low magnetic hysteresis, low coercivity) and the magnetically harder character of martensite phases (in the case of $\left.\mathrm{Ni}_{50} \mathrm{Mn}_{36} \mathrm{Sn}_{13} \mathrm{Pd}_{1}\right)$. This is consistent with the XRD analysis.
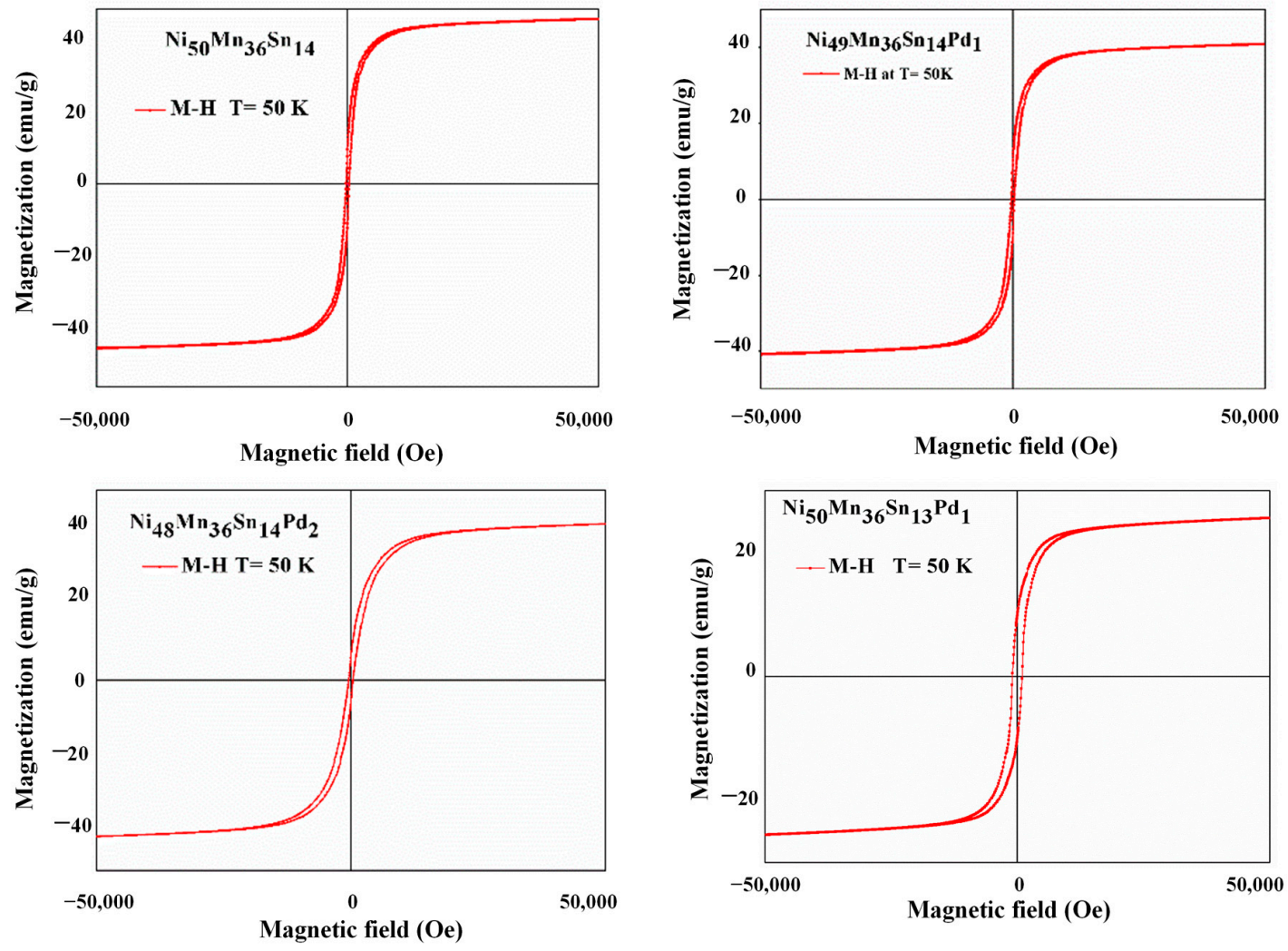

Figure 6. Hysteresis loops measured at $50 \mathrm{~K}$ of $\mathrm{Ni}_{50} \mathrm{Mn}_{36} \mathrm{Sn}_{14}, \mathrm{Ni}_{50} \mathrm{Mn}_{36} \mathrm{Sn}_{13} \mathrm{Pd}_{1}, \mathrm{Ni}_{48} \mathrm{Mn}_{36} \mathrm{Sn}_{14} \mathrm{Pd}_{2}$ and $\mathrm{Ni}_{49} \mathrm{Mn}_{36} \mathrm{Sn}_{14} \mathrm{Pd}_{1}$.

The austenitic phase has a soft ferromagnetic response. It is associated with its low magneto-crystalline anisotropy [34], due to the highly ordered crystallographic cubic phase. Likewise, the magnetic character of the martensite phase is usually accompanied by: (a) high magnetization of saturation (low fields) and (b) fast tendency to saturate. Several authors have seen the same behaviour, such as L. González-Legarreta et al. [32]. 
It is worth pointing out that the magnetic entropy changes in materials with MCE, the first-order magneto-structural transformations can be analysed from thermomagnetic scans under isofield or isothermal conditions. Isofield measurements inform us about: (a) critical temperatures and (b) hysteresis temperature width. Besides, isothermal scans lead to the computation of the isothermal magnetic entropy evolution (due to MCE), as expected from Maxwell relations.

In our case, isofield and isothermal data present a similar tendency and hence, ought to seem identical [35]. The isothermal measurements process consists of several well-known steps [34].

The full M-H hysteresis loops of $\mathrm{Ni}_{50} \mathrm{Mn}_{36} \mathrm{Sn}_{13} \mathrm{Pd}_{1}$ (alloy with structural transformation and Curie temperatures close to room temperature) were registered during both increasing and decreasing fields at several temperatures. This alloy was also selected because it is known that the variation of the total entropy of the martensitic transformation increases exponentially as decreasing the value of $\mathrm{T}_{C}{ }^{\mathrm{A}}-\mathrm{T}_{0}$ difference [36]. For the sake of data clarity in this alloy, only those measured during increasing fields are shown in Figure 7.

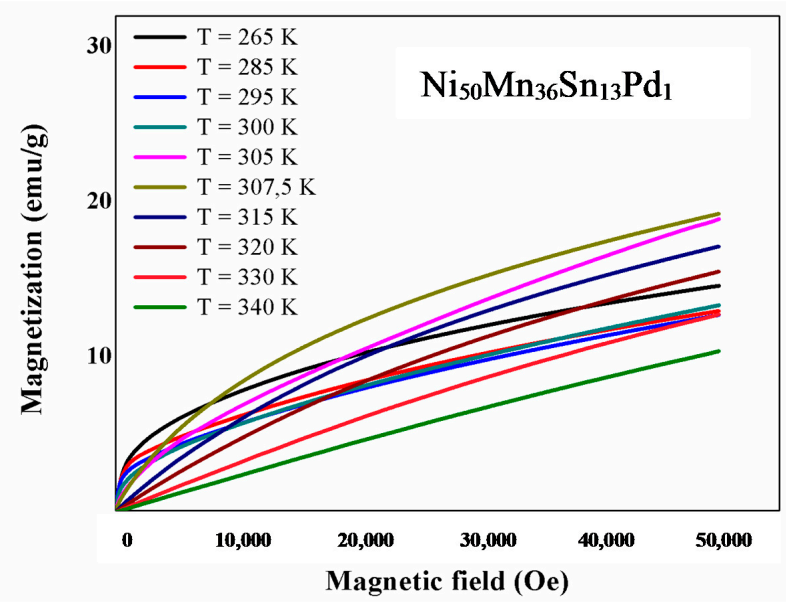

Figure 7. Magnetization as a function of the applied magnetic field (isothermal scans) for $\mathrm{Ni}_{50} \mathrm{Mn}_{36} \mathrm{Sn}_{13} \mathrm{Pd}_{1}$ alloy.

The M-H curves demonstrate a sigmoid shape; as the temperature evolves, the magnetization follows a random order. A further rise in temperature causes a decline in the magnetization (found in isotherms between 305 and $340 \mathrm{~K}$ ). This phenomenon is due to the second-order (ferromagnetic to paramagnetic) magnetic state change of austenite in the vicinity of $\mathrm{T}_{\mathrm{C}}{ }^{\mathrm{A}}$. One can remark that the magnetization does not get saturation even in a magnetic field of $50 \mathrm{kOe}$. As previously remarked, the $\mathrm{Ni}_{50} \mathrm{Mn}_{36} \mathrm{Sn}_{13} \mathrm{Pd}_{1}$ ribbon has a martensitic formation in the ferromagnetic state. This effect is recognized by the curvature of $\mathrm{M}(\mathrm{H})$ scans at the temperature interval where the martensite transformation occurs $\left(\mathrm{T}_{0}\right)$. Furthermore, the alloy unveils much-weakened magnetization of $\sim 9 \mathrm{emu} / \mathrm{g}$ at $340 \mathrm{~K}$ with a rectilinear curve. This designates the presence of non-ferromagnetic nature and the predominance of paramagnetic nature at this temperature step [33].

The magnetic entropy change $\left(\Delta S_{M}\right)$, is considered as a distinctive parameter of the MCE, and frequently is calculated by integration of the Maxwell equation [37]:

$$
\left(\frac{\partial \mathrm{s}}{\partial \mathrm{H}}\right)_{\mathrm{T}}=\left(\frac{\partial \mathrm{M}}{\partial \mathrm{T}}\right)_{\mathrm{H}}
$$

Yet,

$$
\Delta \mathrm{SM}(\mathrm{T}, \mathrm{H})=\mathrm{SM}(\mathrm{T}, H)-\mathrm{SM}(\mathrm{T}, 0)=\int_{0}^{\mathrm{H}}\left(\frac{\partial \mathrm{S}_{\mathrm{M}}}{\partial \mathrm{H}}\right)_{\mathrm{T}} \mathrm{dH}=\int_{0}^{\mathrm{H}}\left(\frac{\partial \mathrm{M}}{\partial \mathrm{T}}\right)_{\mathrm{H}} \mathrm{dH}
$$


We must note that $S_{M}(T, H)$ is the magnetic entropy $(\mathrm{H}$ and $\mathrm{T}$ fixed). Once we remove the magnetic field, we obtain the magnetic entropy $S_{M}(T, 0)$ at temperature $T$. The magnetization scans are executed with low $\mathrm{T}$ and $\mathrm{H}$ step intervals. In this circumstance; the numerical approach of the integral can be used:

$$
\Delta S_{M}=\sum_{i} \frac{M_{i}-M_{i}+1}{T_{i}-T_{i}+1} \Delta H_{i}
$$

where $M_{i} / M_{i}+1$ are the magnetizations at temperatures $T_{i} / T_{i}+1$, respectively. As seen in Equation (1), normally, in the ferromagnetic shape memory alloys, a large magnetization change is usually associated with a large $\Delta S[38]$.

Below Ms, as shown in Figure $8 \Delta S>0$ and, thus, exhibit an inverse MCE. The curves prove the apparition of a peak around the martensitic transformation temperature. Simply put, the inverse effect happens when the transformation takes place between a high (both temperature and magnetization) phase to a low (both temperature and magnetization) phase [38]. The maxima in $\Delta S$ change is approximately $4.5 \mathrm{~J} /(\mathrm{KgK})$ for an applied magnetic field of $50 \mathrm{kOe}$. Likewise, $\Delta \mathrm{S}$ moves to a negative value when $T>T_{C}$. Usually, $\Delta S$ is insignificant in this temperature interval since the magnetic transition is of second order and $\mathrm{M}$ fluctuates over a wide range of temperatures if compared with structural transformation. The coexistence of both reversible transformations (direct and inverse) seems like a shortcoming of these systems, even though, positive and negative $\Delta S$ values can be complementary along a cyclic process. However, it should be contemplated as a beneficial profile in the development of materials and devices for MCE. If a suitable refrigeration cyclic process is assumed, there will be a chance to exploit both contributions to obtain cooling refrigeration [39].

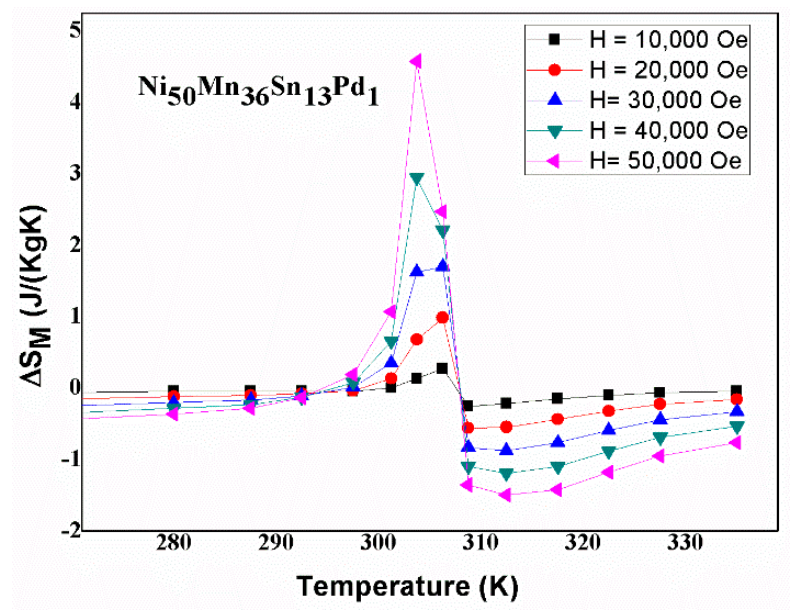

Figure 8. Magnetic entropy evolution as a function of temperature (magnetic field from 10 to $50 \mathrm{kOe}$ ).

Frequently, the Ni-Mn-Sn alloys are described as materials with a substantial $\Delta S>0$ below Ms [40]. This upshot is linked to the structural transformation that befalls in this system. This leads to a diminished magnetization. This is coherent with ab initio $\mathrm{Ni}_{2} \mathrm{MnSn}$ analysis found in the literature [41].

A huge or insignificant value of $\left(\Delta S_{M}\right)^{\text {max }}$ does not essentially inform us about the usefulness of the material for magnetic refrigeration. There are some quantitative parameters associated with the characterization of the magnetocaloric effect and its refrigeration capacity, as the relative cooling power (RCP). RCP is linked to the quantity of thermal energy that is transported between cold and hot sources in an ideal refrigeration cycle. The RCP parameter is calculated by numerical integration of the area under the $\Delta \mathrm{S}_{\mathrm{M}}(\mathrm{T})$ curve by applying the following expression [42]:

$$
R C P=\int_{T_{1}}^{T_{2}} \Delta S_{M}(T) d T
$$


Otherwise, the RCP is also assessed as RCP $=\left(\Delta \mathrm{S}_{\mathrm{M}}\right)^{\max } \times \delta \mathrm{T}_{\mathrm{FWHM}}$. In this study, the calculated (integration) refrigeration capacity value is $28 \mathrm{~J} / \mathrm{kg}$. Typical values found in the scientific literature for ternary and quaternary Ni-Mn-Sn based alloys range between 15 and $30 \mathrm{~J} / \mathrm{Kg}$ [43]. Thus, Pd substitution in $\mathrm{Z}$ sites is an alternative to develop these alloys with improved magnetocaloric effect near room temperature by modifying the Pd content.

\section{Conclusions}

Several melt-spun Ni-Mn-Sn-Pd alloys were produced and analysed (martensitic transformation, magnetic behaviour and magnetocaloric effect). It was remarked that magnetic properties and the martensitic transition are sensitive to the Pd content, even in minor amounts. XRD measurements prove that the structure is an $\mathrm{L} 2{ }_{1}$ austenitic state when $\mathrm{x}=1$ and 2 (X sites of the Heusler structure, Ni substitution), and a modulated monoclinic martensitic structure with Pd substitution on the $\mathrm{Z}$ sites. The martensitic start temperature increases from 194 to $233 \mathrm{~K}$, by means of the increase in the Pd substitution of Ni. Moreover, Pd replacement of Sn alters meaningfully the martensitic transformation to high temperatures from 194 to $295 \mathrm{~K}$. The maximum value of isothermal magnetic entropy change $\left(\Delta \mathrm{S}_{\mathrm{M}}{ }^{\mathrm{max}}\right)$ is $4.5 \mathrm{~J} / \mathrm{kg} \mathrm{K}$ for a field change of $50 \mathrm{kOe}$ in the $\mathrm{Ni}_{50} \mathrm{Mn}_{36} \mathrm{Sn}_{13} \mathrm{Pd}_{1}$ alloy. This alloy has both structural and magnetic transformations near room temperature. Furthermore, a value of refrigeration capacity of $24 \mathrm{~J} / \mathrm{kg}$ under $50 \mathrm{kOe}$ was calculated. The possibility to shift characteristic temperatures with $\mathrm{Pd}$ content and the RCP value rises the chances to make this alloy (in comparison to other Ni-Mn-based alloys) a potential material to be introduced in magnetic refrigeration devices.

Author Contributions: Conceptualization, M.K. and J.-J.S.; methodology, J.-J.S., L.E. and M.I.; formal analysis, M.I. and A.W.; investigation, A.W.; resources, E.P. and J.-M.G.; writing-original draft preparation, A.W. and J.-J.S.; funding acquisition, J.-J.S. All authors have read and agreed to the published version of the manuscript.

Funding: This research was funded by MINECO grant MAT2016-75967-P and UdG grant PONT2020/01.

Acknowledgments: The authors agree technical support from SGYKER labs (EHU/UPV) and STR (UdG).

Conflicts of Interest: No conflict of interest is declared by the authors.

\section{References}

1. Kök, M.; Durğun, S.B.; Özen, E. Thermal analysis, crystal structure and magnetic properties of Cr-doped Ni-Mn-Sn high-temperature magnetic shape memory alloys. J. Therm. Anal. Calorim. 2019, 136, 1147-1152. [CrossRef]

2. Gruner, M.E.; Niemann, R.; Entel, P.; Pentcheva, R.; Rößler, U.K.; Nielsch, K.; Fähler, S. Modulations in martensitic Heusler alloys originate from nanotwin ordering. Sci. Rep. 2018, 8. [CrossRef] [PubMed]

3. Coll, R.; Escoda, L.; Saurina, J.; Sánchez-Llamazares, J.L.; Hernando, B.; Suñol, J.J. Martensitic transformation in Mn-Ni-Sn Heusler alloys. J. Therm. Anal. Calorim. 2010, 99, 905-909. [CrossRef]

4. Bachaga, T.; Daly, R.; Escoda, L.; Sunol, J.J.; Khitouni, M. Influence of chemical composition on martensitic transformation of MnNiIn shape memory alloys. J. Therm. Anal. Calorim. 2015, 122, 167-173. [CrossRef]

5. Zhang, K.; Tan, C.; Guo, E.; Feng, Z.; Zhu, J.; Tong, Y.; Cai, W. Simultaneous tuning of martensitic transformation behavior, magnetic and mechanical properties in Ni-Mn-Sn magnetic alloy by $\mathrm{Cu}$ doping. J. Mater. Chem. C 2018, 6, 5228-5238. [CrossRef]

6. Maji, B.; Ray, M.K.; Modak, M.; Mondal, S.; Suresh, K.G.; Banerjee, S. Magnetic properties and large reversible magnetocaloric effect in Er3Pd2. J. Magn. Magn. Mater. 2018, 456, 236-240. [CrossRef]

7. Pérez-Landazábal, J.I.; Recarte, V.; Sánchez-Alarcos, V.; Beto-López, J.J.; Rodríguez-Velamazán, J.A.; Sánchez-Marcos, J.; Gómez-Polo, E.; Cesari, E. Giant direct and inverse magnetocloric effect linked to the same forward martensitic transformation. Sci. Rep. 2017, 7, 13328. [CrossRef]

8. Ghosh, A.; Rawat, R.; Bhattacharyya, A.; Mandal, G.; Nigam, A.K.; Nair, S. Measurement independent magnetocaloric effect in Mn-rich Mn-Fe-Ni-Sn(Sb/In) Heusler alloys. J. Magn. Magn. Mater. 2019, 476, 92-99. [CrossRef] 
9. Kainuma, R.; Imano, Y.; Ito, W.; Sutou, Y.; Morito, H.; Okamoto, S.; Kitakami, O.; Oikawa, K.; Fujita, A.; Kanomata, T.; et al. Magnetic-field-induced shape recovery by reverse phase transformation. Nature 2006, 439, 957-960. [CrossRef]

10. Li, Z.B.; Yang, B.; Zhang, Y.D.; Esling, C.; Zhao, X.; Zuo, L. Influence of Cu doping on martensitic and magnetic transitions in Ni-Mn-Sn alloys. Mater. Sci. Forum 2017, 879, 1123-1128. [CrossRef]

11. Wederni, A.; Ipatov, M.; Pineda, E.; Suñol, J.-J.; Escoda, L.; González, J.M.; Alleg, S.; Khitouni, M.; Żuberek, R.; Chumak, O.; et al. Magnetic properties, martensitic and magnetostructural transformations of ferromagnetic Ni-Mn-Sn-Cu shape memory alloys. Appl. Phys. A 2020, 126, 320. [CrossRef]

12. Zhang, X.; Zhang, H.; Qian, M.; Geng, L. Enhanced magnetocaloric effect in Ni-Mn-Sn-Co alloys with two successive magnetostructural transformations. Sci. Rep. 2018, 8, 8235. [CrossRef]

13. Chen, C.; Yu, L.; Zhu, J.; Tan, C. The mechanical properties of Ni-Mn-Sn Alloy thin films with Fe doping. Integr. Ferroelectr. 2020, 207, 156-165. [CrossRef]

14. Inallu, M.N.; Kameli, P.; Varzaneh, A.G.; Sarsari, I.A.; Salazar, D.; Orue, I.; Chernenko, V.A. Magnetocaloric effect in W-doped Ni-Mn-Sn alloy probed by direct and indirect measurements. J. Phys. D Appl. Phys. 2019, 52. [CrossRef]

15. Dong, S.Y.; Chen, J.Y.; Han, Z.D.; Fang, Y.; Zhang, L.; Zhang, C.L.; Qian, B.; Jiang, X.F. Intermartensitic transformation and enhanced exchange bias in $\mathrm{Pd}(\mathrm{Pt})$-doped Ni-Mn-Sn alloys. Sci. Rep. 2016, 6. [CrossRef]

16. Himmetoglu, B.; Katukuri, V.M.; Cococcioni, M. Origin of magnetic interactions and their influence on the structural properties of $\mathrm{Ni} 2 \mathrm{MnGa}$ and related compounds related content origin of magnetic interactions and their influence on the structural properties of Ni $2 \mathrm{MnGa}$ and related compounds. J. Phys. Condens. Matter 2012, 24, 15. [CrossRef] [PubMed]

17. Saha, R.; Nigam, A.K. Room temperature inverse magnetocaloric effect in Pd substituted $\mathrm{Ni}_{50} \mathrm{Mn}_{37} \mathrm{Sn}_{13}$ Heusler alloys. Phys. B Condens. Matter 2014, 448, 263-266. [CrossRef]

18. Lutterotti, L.; Matthies, S.; Wenk, H.R. Quantitative phase analysis. Newsl. CPD 1999, 21, $14-15$.

19. Quintana-Nedelcos, A.; Llamazares, J.L.S.; Ríos-Jara, D.; Lara-Rodríguez, A.G.; García-Fernández, T. Effect of quenching rate on the average grain size and martensitic transformation temperature in rapidly solidified polycrystalline $\mathrm{Ni}_{50} \mathrm{Mn}_{37} \mathrm{Sn}_{13}$ alloy ribbons. Phys. Status Solidi 2013, 210, 2159-2165. [CrossRef]

20. Krenke, T.; Moya, X.; Aksoy, S.; Acet, M.; Entel, P.; Mañosa, L.; Planes, A.; Elerman, Y.; Yücel, A.; Wassermann, E.F. Electronic aspects of the martensitic transition in Ni-Mn based Heusler alloys. J. Magn. Magn. Mater. 2007, 310, 2788-2789. [CrossRef]

21. Rietveld, H.M. A profile refinement method for nuclear and magnetic structures. J. Appl. Crystallogr. 1969, 2, 65-71. [CrossRef]

22. Bachaga, T.; Daly, R.; Khitouni, M.; Escoda, L.; Saurina, J.; Suñol, J. Thermal and structural analysis of Mn49.3Ni43.7Sn7.0 Heusler alloy ribbons. Entropy 2015, 17, 646-657. [CrossRef]

23. Qu, Y.H.; Cong, D.Y.; Sun, X.M.; Nie, Z.H.; Gui, W.Y.; Li, R.G.; Ren, Y.; Wang, Y.D. Giant and reversible room-temperature magnetocaloric effect in Ti-doped Ni-Co-Mn-Sn magnetic shape memory alloys. Acta Mater. 2017, 134, 236-248. [CrossRef]

24. Emre, B.; Yuce, S.; Bruno, N.M.; Karaman, I. Martensitic transformation and magnetocaloric properties of NiCoMnSn magnetic shape memory alloys. Intermetallics 2019, 106, 65-70. [CrossRef]

25. Czaja, P.; Kowalczyk, M.; Maziarz, W. On the magnetic contribution to the inverse magnetocaloric effect in Ni-Co-Cu-Mn-Sn metamagnetic shape memory alloys. J. Magn. Magn. Mater. 2019, 474, 381-392. [CrossRef]

26. Xuan, H.C.; Xie, K.X.; Wang, D.H.; Han, Z.D.; Zhang, C.L.; Gu, B.X.; Du, Y.W. Effect of annealing on the martensitic transformation and magnetocaloric effect in Ni44.1Mn44.2Sn11.7 ribbons. Appl. Phys. Lett. 2008, 92, 242506. [CrossRef]

27. Xing, C.; Zhang, H.; Long, K.; Xiao, Y.; Zhang, H.; Qiu, Z.; He, D.; Liu, X.; Zhang, Y.; Long, Y. The effect of different atomic substitution at Mn site on magnetocaloric effect in Ni50Mn35Co2Sn13 alloy. Crystals 2018, 8, 329. [CrossRef]

28. Pataky, G.J.; Ertekin, E.; Sehitoglu, H. Elastocaloric cooling potential of NiTi, Ni2FeGa, and CoNiAl. Acta Mater. 2015, 96, 420-427. [CrossRef]

29. Louidi, S.; Sunol, J.J.; Ipatov, M.; Hernando, B. Effect of cobalt doping on martensitic transformations and the magnetic properties of Ni 50-x Co x Mn 37 Sn 13 ( $x=1,2,3)$ Heusler ribbons. J. Alloys Compd. 2018, 739, 305-310. [CrossRef] 
30. Bachaga, T.; Daly, R.; Suñol, J.J.; Saurina, J.; Escoda, L.; Legarreta, L.G.; Hernando, B.; Khitouni, M. Effects of Co additions on the martensitic transformation and magnetic properties of Ni-Mn-Sn shape memory alloys. J. Supercond. Nov. Magn. 2015, 28, 3087-3092. [CrossRef]

31. Dubenko, I.; Ali, N.; Stadler, S.; Zhukov, A.; Zhukova, V.; Hernando, B.; Prida, V.; Prudnikov, V.; Gan'shina, E.; Granovsky, A. Magnetic, magnetocaloric, magnetotransport, and magneto-optical properties of Ni-Mn-In-based Heusler alloys: Bulk, ribbons, and microwires. In Novel Functional Magnetic Materials; Springer: Cham, Switzerland, 2016; pp. 41-82.

32. González-Legarreta, L.; Caballero-Flores, R.; Rosa, W.O.; Ipatov, M.; Escoda, L.; Suñol, J.J.; Prida, V.M.; González, J.; Hernando, B. Heusler alloy ribbons: Structure, martensitic transformation, magnetic transitions, and exchange bias effect. In Novel Functional Magnetic Materials; Springer: Cham, Switzerland, 2016; pp. 83-114.

33. Wu, Z.; Guo, J.; Liang, Z.; Zhang, Y.; Ye, X.; Zhang, J.; Li, Y.; Liu, Y.; Yang, H. Room temperature metamagnetic transformation of a tough dual-phase Ni-Mn-Sn-Fe ferromagnetic shape memory alloy. J. Alloys Compd. 2020, 829, 154606. [CrossRef]

34. Hernando, B.; Llamazares, J.L.S.; Santos, J.D.; Sánchez, M.L.; Escoda, L.; Suñol, J.J.; Varga, R.; García, C.; González, J. Grain oriented NiMnSn and NiMnIn Heusler alloys ribbons produced by melt spinning: Martensitic transformation and magnetic properties. J. Magn. Magn. Mater. 2009, 321, 763-768. [CrossRef]

35. Caron, L.; Ou, Z.Q.; Nguyen, T.T.; Cam Thanh, D.T.; Tegus, O.; Brück, E. On the determination of the magnetic entropy change in materials with first-order transitions. J. Magn. Magn. Mater. 2009, 321, 3559-3566. [CrossRef]

36. Aguilar-Ortiz, C.O.; Soto-Parra, D.; Álvarez-Alonso, P.; Lázpita, P.; Salazar, D.; Castillo-Villa, P.O.; Flores-Zúñiga, H.; Chernenko, V.A. Influence of Fe doping and magnetic field on martensitic transition in Ni-Mn-Sn melt-spun ribbons. Acta Mater. 2016, 107, 9-16. [CrossRef]

37. Zheng, Q.; Zhang, L.; Du, J. Table-like magnetocaloric effect in Gd-Ni-Al amorphous/nanocrystalline composites. J. Phys. D Appl. Phys. 2017, 50, 355601. [CrossRef]

38. Liu, Z.H.; Aksoy, S.; Acet, M. Influence of Sb on the magnetic and magnetocaloric properties of ferromagnetic shape memory alloy NiMnIn. J. Appl. Phys. 2009, 105. [CrossRef]

39. Fabbrici, S.; Kamarad, J.; Arnold, Z.; Casoli, F.; Paoluzi, A.; Bolzoni, F.; Cabassi, R.; Solzi, M.; Porcari, G.; Pernechele, C.; et al. From direct to inverse giant magnetocaloric effect in Co-doped NiMnGa multifunctional alloys. Acta Mater. 2011, 59, 412-419. [CrossRef]

40. Krenke, T.; Duman, E.; Acet, M.; Wassermann, E.F.; Moya, X.; Mañosa, L.; Planes, A. Inverse magnetocaloric effect in ferromagnetic Ni-Mn-Sn alloys. Nat. Mater. 2005, 4, 450-454. [CrossRef]

41. Sasioglu, E.; Sandratskii, L.M.; Bruno, P. First-principles calculation of the intersublattice exchange interactions and Curie temperatures of full Heusler alloys Ni2MnX (X = Ga, In, Sn, Sb). Phys. Rev. B Condens. Matter Mater. Phys. 2004, 70. [CrossRef]

42. Provenzano, V.; Shapiro, A.J.; Shull, R.D. Reduction of hysteresis losses in the magnetic refrigerant Gd 5Ge2Si2 by the addition of iron. Nature 2004, 429, 853-857. [CrossRef]

43. Modak, R.; Manvel Raja, M.; Srinivasan, A. Enhanced magento-caloric effect upon fourt element (Cu, $\mathrm{Fe}, \mathrm{Co})$ substitution in Ni-Mn-Sn thin films. Appl. Phys. A 2019, 125, 57. [CrossRef]

Publisher's Note: MDPI stays neutral with regard to jurisdictional claims in published maps and institutional affiliations.

(C) 2020 by the authors. Licensee MDPI, Basel, Switzerland. This article is an open access article distributed under the terms and conditions of the Creative Commons Attribution (CC BY) license (http://creativecommons.org/licenses/by/4.0/). 